\title{
Profiles of personal and ecological assets: Adolescents' motivation and engagement in self-driven learning
}

\author{
Gaoxia Zhu' ${ }^{1}$. Anthony L. Burrow ${ }^{1}$ \\ Accepted: 17 October 2021 \\ (c) The Author(s), under exclusive licence to Springer Science+Business Media, LLC, part of Springer Nature 2021
}

\begin{abstract}
While opportunities for adolescents to drive their own learning are increasing, differences in motivations for and engagement in these opportunities are rarely investigated. The current study employed a sample of adolescents $\left(N=580, M_{\text {age }}=16.53\right)$ enrolled in GripTape, a 10-week self-driven learning program in which youth pursue topics of their choosing. Cluster analysis classified adolescents based on their personal (e.g., resilience, competence) and ecological (e.g., adult support, safe environments) assets, resulting in two distinguishable groups. A High Asset group scored more favorably on these indicators than a Lower Asset group. Between-cluster comparisons revealed that compared to the Lower Asset group, the High Asset group reported greater levels of motivation for self-driven learning (i.e., intrinsic, extrinsic, and competence demonstration), but not engagement (i.e., positive learning experience, commitment to learning topics and activities). Subsequent tests showed that extrinsic motivation and competence demonstration negatively correlates with youth commitment to learning topics and activities. These findings enrich the literature concerning adolescents' motivations for and engagement in self-driven learning, and how to support youth self-driven learning.
\end{abstract}

Keywords Self-driven learning $\cdot$ Adolescent $\cdot$ Motivation $\cdot$ Resilience $\cdot$ Ecological asset

Research suggests that during adolescence, individuals develop more refined cognitive, affective, and self-regulatory abilities which enable them to adaptively pursue new goals and seek novelty and excitement (Dahl et al., 2018; Steinberg, 2015). In recognition of these changes, opportunities for adolescents to guide their own learning and student-centered learning are growing in abundance and quality across educational landscapes. These opportunities can be found in both formal and informal learning contexts, and manifest in a variety of recognized forms including active learning, independent learning, ownership learning, and self-driven learning (e.g., Broad, 2006; Kopzhassarova et al., 2016; Lee, 2020; Meyer, 2010; Motjolopane, 2021). Despite subtle differences in definition, each of these forms of learning emphasizes student autonomy and control to a greater extent than traditional forms of instruction (Motjolopane, 2021), enabling learners to decide what they are interested in, how they should work towards goals, monitor

Gaoxia Zhu

gaoxia.zhu@cornell.edu

1 Department of Psychology, Cornell University, office G122B

Martha Van Rensselaer, Ithaca, NY 14853, USA progress, and assess achievements. An overarching aim of these opportunities is to enhance student engagement and the quality of learning by emphasizing students' own responsibility, agency, and motivations for pursuing meaningful goals (Ferlazzo, 2013).

Despite the proliferation of opportunities to direct one's own learning, the personal and ecological assets of adolescents most interested in these experiences have not been fully explored. Rarer still, are investigations into what motivates adolescents to seek out opportunities to drive their own learning in the first place, and what keeps them engaged when they do. Such questions can be explored within the context of GripTape, a self-driven learning program that invites ethnically and socioeconomically diverse adolescents from across the United States to direct their own learning on any topic or skill they choose. Capitalizing on the rich diversity of youth enrolled in this program we identified unique profiles of adolescents and explored how they were differentially motivated for and engaged in their learning. Findings from this research could shed new light on strategies for enhancing youth engagement in self-driven learning. 


\section{Engagement in Self-Driven Learning}

Engagement refers to adolescents' degree of involvement concerning interest, effort, and enjoyment in an activity (Mahoney et al., 2009). It is positively associated with academic achievement in various domains, and social and emotional learning outcomes (Klem \& Connell, 2004). Much research on engagement has been conducted in the formal learning context (Christenson et al., 2012; Schmidt et al., 2020), while recent years witness an increasing trend to employ the framework of engagement to understand learners' learning experiences out of school (Bell et al., 2019; Christenson et al., 2012). For instance, Shernoff and Vandell (2007, p. 891) conceptualized student engagement as "the simultaneous experience of concentration, interest, and enjoyment" and measured students' engagement in after-of-school activities using the experience sampling method. They found that students reported higher levels of engagement when participating in after-school sport and art activities than when completing homework at programs. Schmidt et al. (2020) researched how youth experiences (e.g., challenge, relevance) are associated with their engagement in summer STEM programs. They measured youth momentary engagement using four items focusing on the levels of their hard work, concentration, enjoyment, and interest and found that when the youth perceived the program activities to be more challenging and relevant and to have more affordances for their development and learning, they tended to report higher engagement (Schmidt et al., 2020). Similarly, this study measured engagement through youth perceived enjoyment in and commitment to their self-driven learning.

The conceptualization of engagement highly depends on context (Schmidt et al., 2020), which indicates that research on engagement conducted in the formal learning context may not be directly applied to informal, or more specifically, youth self-driven learning context. As a result, our understanding of the extent to which adolescents engage in self-driven learning in which they take leadership roles and can determine their own learning topics and paths is limited. Furthermore, how other factors, such as youth personal and ecological assets, and motivations correlate with their engagement in self-driven learning remain uninvestigated. This exploratory study aimed to respond to these research gaps and extend our understanding of the motivation for and engagement in self-driven learning of youth with different personal and ecological assets. Given the uniqueness of the self-driven learning of this current study - enabling youth to choose their own learning topics and activities - the extent to which youth commit to the topics and activities of their choosing reflects their levels of engagement. Therefore, in addition to measure youth's levels of enjoyment and interest, we added several items to measure youth commitment to their learning topics and activities as part of our engagement scale.

\section{Motivations for Self-Driven Learning}

Longstanding perspectives on what motivates students to learn (e.g., Self Determination Theory; Ryan \& Deci, 2000; Vansteenkiste et al., 2006) point to a bifurcation of influences that can be broadly qualified as intrinsic and extrinsic. Whereas intrinsically motivated students are driven by their own interest, enjoyment, and satisfaction for learning, extrinsically motivated students attend primarily to external rewards and consequences that they believe obtainable with having learned something. This distinction may vary in magnitude within individuals - indeed, a student may, at times, experience both intrinsic and extrinsic motivations to learn. Yet, there is ample evidence that stronger intrinsic motivations for learning tend to be adaptive, corresponding with higher quality learning (Vansteenkiste et al., 2004), better academic performance (Cerasoli et al., 2014), and enhanced creativity (Ryan \& Deci, 2000).

Adolescence is a critical period for investigating motivations for learning, given the consolidation of one's sense of autonomy, self, and identity is understood as central to this developmental period. Adolescents increasingly demonstrate a need for independence, personal agency, responsibility, and autonomy (Earl et al., 2017), which is a fundamental motive for intrinsic motivation (Ryan \& Deci, 2017; Vansteenkiste et al., 2006). According to the Cognitive Evaluation Theory (CET; Deci \& Ryan, 1985), social and environmental factors such as optimal challenges, feedback, choice, and the opportunity for self-direction facilitate intrinsic motivation as a result of satisfying the basic psychological need for competence. However, research suggests that as people grow older, intrinsic motivation weakens while extrinsic motivation increases because of increasing social demands and individual responsibilities curtail the freedom to be intrinsically motivated (Ryan \& Deci, 2000). A longitudinal study (Gottfried et al., 2001) suggested that students' mean level of academic intrinsic motivation decreases from childhood to late adolescence but is modified by subject areas. This is relevant with an important feature of intrinsic motivation - topic-specificity, which suggests that a person may be internally interested in some topics but not others. To the extent that self-driven learning opportunities allow individual learners to select topics they perceive as meaningful and important, one might expect adolescents would demonstrate high intrinsic motivation when provided with such opportunities. 


\section{Adolescents Personal (i.e., Resilience, Competence) and Ecological (e.g., Adult Support, Safe Environments) Assets}

Both personal characteristics and the broader ecologies in which they are situated may influence youth engagement in out-of-school activities and their development (Mahoney et al., 2009). The Social Cognitive Theory (Bandura, 1999) posits that individual behaviors are influenced by personal factors and traits as well as social environmental factors. Therefore, this study considered adolescents' personal (i.e., resilience, competence) ecological (e.g., adult support, safe environments, the value of school learning) assets when researching their engagement in out-of-school self-driven learning. The reasons for choosing these factors are elaborated as follows:

Personal competence is a central determinant of engagement (Mahoney et al., 2009). Prior knowledge or skills is related to cognitive competence and ability (Kumar et al., 2018). Students' prior knowledge or skills regarding a learning challenge tend to impact their perceived competence for accomplishing it. Individuals are more likely to experience engagement when there is a balance between their perceived competence in an area and the challenges involved in tasks (Csikszentmihalyi \& Schneider, 2000). Furthermore, perceived competence tends to be related to one's resilience. Individuals who have higher competence at a task tend to endorse approach achievement goals and be more resilient to failure, while the ones who are not confident with their competence are more likely to endorse avoidance achievement goals and react more strongly to failure (Cury et al., 2006).

Resilience is about the ability to adapt successfully and maintain or regain mental health in the face of stress and adversity (Wu et al., 2013). It is essential for success in school and life given that challenges are ubiquitous. Individuals develop resilience through interactions with environments (Rutter, 2006). In the self-driven learning context, when less structure but greater autonomy is provided, youth may experience positive affects; but on the other hand, they may experience challenges and frustrations (Reynolds \& Caperton, 2011). How youth respond to the challenges and frustrations emerging during their learning process is likely to influence their engagement in learning.

Personal assets affect and are affected by the ecological assets (e.g., parents, school, and neighborhood) in which they interact and develop (Mahoney et al., 2009). The ecological assets may include aspects of adult support and help; safety of the school, home, and neighborhood; the value of school learning; and the importance of doing well in school to their future goals. All students deserve a safe, respectful, positive, and caring learning environment in which they feel belonged, are respected and cared for, joyful, and responsible. Previous studies (e.g., Lizzio et al., 2002; Raufelder \& Kulakow, 2021), which tend to focus on the school environment, have found connections between the ecological assets and students' academic achievement, self-efficacy, and satisfaction. Hamid et al. (2013) suggested that students who perceive the ecological assets as more favorably tend to have greater learning achievement than those who do not. In turn, Ahmed et al. (2018) found that compared with low achievers, high achievers perceive their ecological assets significantly more positively.

\section{The Current Study}

The current study aimed to explore how adolescents' personal and ecological assets might converge into unique profiles, and how these profiles might correspond with different kinds of motivations for and engagement in self-driven learning. The GripTape self-driven learning program provides a unique setting for conducting this study because it enables adolescents to choose learning topics that they consider as meaningful and realistic and fit their competence. We explored four questions:

1. Can adolescents be classified into unique clusters based on their personal and (e.g., resilience, competence) and ecological (e.g., adult support, safe environments) assets?

2. Do the emergent clusters differ in their motivations for self-driven learning?

3. Do different types of adolescents engage in self-driven learning differently?

4. What factors correlates with adolescents' engagement in self-driven learning?

\section{Method}

\section{Participants}

There were 1217 adolescents accepted by the GripTape project. Among them, 580 adolescents completed the presurvey and filled in the post-survey concerning the relevant measurements. The 580 adolescents were included in this study, and 212 were males $(36.55 \%), 353$ were females $(60.86 \%)$, and 15 were others. Their age ranged from 15 to 19 years $(M=16.53)$. Regarding the race/ethnicity of the participants, $21.72 \%$ identified as Black or African American; $19.14 \%$ identified as Hispanic or Latino; $17.59 \%$ identified as White, Non-Hispanic; $13.28 \%$ identified as Asian; $2.76 \%$ identified as American Indian or Alaska Native; 
$0.52 \%$ identified as Native Hawaiian or Other Pacific Islander; the rest of the participants either reported others or did not report the race/ethnicity information.

\section{Procedure}

The data were collected by the GripTape team (https:// griptape.org/) from 2016 to 2020 for internal evaluation and future research purposes. The GripTape project offers adolescents between 15- and 19-years old opportunities to pursue learning challenges that they are passionate about. The project is based on a belief that "all young people should have the support and resources to deepen their interests and chart their path to success." Therefore, this project especially targets adolescents who usually do not have access to an abundance of learning resources or support.

After they were accepted by the project and before they started their learning challenges, the adolescents filled out the pre-surveys, including instruments on their resilience, competence, ecological assets, and motivations for selfdriven learning. Then the adolescents were empowered and funded to pursue 10-week or around learning challenges determined by themselves - what they cared about but usually did not have opportunities or resources to pursue. Their learning topics were very diverse and cover most subject areas, such as Computer Science (e.g., Artificial Intelligence, Virtual Reality, R and Python); Arts \& humanities (e.g., Latin American rhythms, photography, Spanish language); Clinical, Pre-clinical \& Health (e.g., cardiovascular surgeon, sports medicine; neurodegenerative disease) and many others. Each adolescent was assigned an adult to encourage them along with their learning challenges (see Learning Challenge Overview for a more detailed description of the project, GripTape, 2021). Finally, the adolescents filled out a post-survey concerning their engagement in self-driven learning. The Institutional Review Board at the authors' university waived the ethics protocol review because we do not have access to the private identifiable information of the participants nor any master list that would allow the re-identification of the data.

\section{Materials}

The instruments were developed by the GripTape team. They first conducted hundreds of interviews with the adolescents to understand what they want and the best ways to support them. Then they honed on the core concept development of agency - "the ability to make intentional choices about and take an active role in the course of one's own learning" (what we refer to as responsibility, control, and agency in this study, see GripTape, 2017). Accordingly, they developed a framework of youth agency which suggests that learner internal locus, learner skills, learner experience, and ecological assets nest conditions and interrelated components for the agency to develop. In this study, resilience, competence, and ecological assets correspond to different layers of the framework. The team adapted relevant instruments to fit the self-driven learning context. We briefly described the instruments here and elaborations on exploratory factor analysis results and final scales can be found in the Supplementary material.

Participants' resilience was measured using a four-point Linkert scale with nine items. On this scale, 1 represents strongly disagree and 4 denotes strongly agree. The nine questions are about the extent to which the learners think they can deal with problems, challenges, and new tasks; believe that hard work and persistence will lead to success; and how calm they would be in facing difficulties. The participants were surveyed on their competence (i.e., perceived knowledge or skills related to the topic that they explored) using one four-point Likert item before they started the challenge. The question is "How would you rate your skills or knowledge in your learning journey topic before starting the journey?" The responses ranged from "no skills or knowledge yet" (1) to "advanced skills or knowledge" (4). The participant's perception of their ecological assets was measured using a four-point Linkert scale (strongly disagree to strongly agree) with thirteen items. The items are about the extent to which the learners think they are supported by adults around them; their home, school, and neighborhood are safe; school is a waste of time and has no connection with their future; doing well in school will benefit their future; they have control over school learning and see the value of what they learn in school.

Participants' motivation for the self-driven learning project was measured using 11 items developed based on the self-determination theory (Deci \& Ryan, 1985) and the nature of the project. There were four response levels to these items: not applicable (0), not important (1), somewhat important (2), and very important (3). The questions are about the extent to which the adolescents think internal factors (e.g., exploring a topic that they are interested in, care about, but do not have other pathways to pursue) and external factors (e.g., receiving funding, recognition, and a letter of recommendation, being encouraged by peers and adults, demonstrating what they can accomplish) influence their decision to apply to the self-driven learning.

The engagement in the self-driven learning instrument measured the participants' experiences throughout the learning challenges. This instrument includes nine five-point Linkert scale items (1 representing strongly disagree and 5 denoting strongly agree) which load onto two factors: positive learning experiences and commitment to learning topics and activities. The positive learning experiences factor consists of six questions about the extent to which the participants enjoy their learning, gain meaningful knowledge or skills, receive helpful support and encouragement and sufficient resources, and 
accomplish their goals. The commitment to learning topics and activities factor includes three questions concerning the extent to which the participants are motivated throughout the learning challenges and would commit to the same learning topics and activities when they have chances to redo the learning.

\section{Analytic Plan}

Because we created scales using a series of discrete items assessed by GripTape surveys, exploratory factor analysis (EFA) was conducted to examine the internal structure of the scales. EFA refers to a set of statistical procedures to determine the number of distinct constructs that account for the pattern of correlations among an instrument (Fabrigar \& Wegener, 2011). In this study, for each measurement, we first conducted a parallel analysis, a technique that compares the scree of factors of the observed data (Buja \& Eyuboglu, 1992), to explore the number of factors. Then we ran a factor analysis using the 'psych' packages to further understand the structures and components (Revelle, 2020). In each measurement, to ensure the validity of the items, we removed the items with a factor loading smaller than 0.30 . The Root Mean Square Residual (RMSR), Root Mean Square Error of Approximation (RMSEA) value, and Tucker-Lewis Index (TLI) were adopted to evaluate the fitness of the models. RMSR $<0.08$ and RMSEA $<0.08$ represent a good fit (Parry, 2021). Regarding TLI, a cutoff value over 0.90 indicates a good fit (Hu \& Bentler, 1999). The internal reliability of each factor in each scale was estimated using Cronbach's (1951) alphas. Cronbach's alpha values above 0.6 are acceptable (e.g., van Griethuijsen et al., 2015). Details of the EFA results, structures, and items of the engagement in self-driven learning, motivation for self-driven learning, resilience, and ecology scales can be found in the Supplementary material. Table 1 shows the descriptive statistics of key research variables and their correlations.

K-Means Cluster Analysis To respond to the first question regarding how adolescents can be classified into distinct groups, we conducted a K-means clustering analysis. Cluster analysis identifies subgroups that have distinct properties and characteristics between groups but similar features within groups in terms of the input elements (Bergey \& Ranellucci, 2021; Hair et al., 1998). We computed the Silhouette coefficient to determine the optimal number of clusters (i.e., the $\mathrm{K}$ value). Silhouette is a visual and classic method for identifying the optimal number of clusters (Kaufman \& Rousseeuw, 2009). The following steps were employed to investigate a stable classification of the participants. First, we conducted cluster analyses with the input information of the 580 participants. The cluster elements were participant's resilience ability, resilience beliefs, resilience attitude, competence, adult support and help, safe environments, the value of school learning, school for future goals, and control-value beliefs. Then we randomly selected half of the participants (i.e., 290) and ran the Silhouette coefficient analysis 30 times to determine the most popular optimal number. Finally, we chose the optimal number and clustered the participants into groups.

T-Test and Multiple Linear Regression To compare the mean difference of motivations for self-driven learning of different clusters (RQ2), we conducted T-tests. Two sample T-test determines whether the means of two independent groups have statistically significant differences. In this study, we used a probability value of 0.05 as the threshold of statistical significance. Similarly, two sample T-tests were conducted to respond to the third research question concerning whether different types of adolescents have different levels of engagement in self-driven learning. Finally, to answer the fourth research question concerning factors correlating with adolescents' engagement in self-driven learning, we conducted multiple regression analyses using adolescents' personal and ecological assets, and motivations for self-driven learning as predicting variables.

\section{Results}

\section{RQ1 Profiles of Adolescents in the Self-Driven Learning}

The repeating Silhouette analysis with the input information of 580 participants, a random selection of half participants from the 580 participants all suggested that two is the optimal number of clustering. Therefore, we classified the 580 participants into two clusters. Figure 1 shows the Silhouette statistic with the input elements of 580 participants, confirming that the K-means clustering has the best performance when the number is set to two.

Table 2 shows the descriptive data of the two clusters. Compared with Cluster $2(\mathrm{n}=263,45.34 \%)$, Cluster 1 $(\mathrm{n}=317,54.66 \%)$ showed significantly higher resilience ability, resilience beliefs, resilience attitude, competence, adult support and help, safe environments, the value of school learning, and school for future goals. These results suggest that two distinct subgroups applied to the self-driven learning project. We labeled Cluster 1 as a High Asset group and Cluster 2 as a Lower Asset group.

\section{RQ2 Motivation Difference among the Identified Clusters}

Table 3 shows the descriptive data of the two clusters in terms of motivations for self-driven learning. T-tests between the two clusters suggest that the High Asset group has significantly greater levels of intrinsic, extrinsic, and 
Table 1 Descriptive statistics of key research variables

\begin{tabular}{|c|c|c|c|c|c|c|c|c|c|c|c|c|c|}
\hline Variable & 1 & 2 & 3 & 4 & 5 & 6 & 7 & 8 & 9 & 10 & 11 & 12 & 13 \\
\hline \multicolumn{14}{|l|}{ 1. ResAb } \\
\hline 2. ResBlf & $0.44 * * *$ & & & & & & & & & & & & \\
\hline 3. ResAttd & $0.48 * * *$ & $0.53 * * *$ & & & & & & & & & & & \\
\hline 4. Com & 0.07 & 0.02 & 0.04 & & & & & & & & & & \\
\hline 5. AdultS & $0.24 * * *$ & $0.22 * * *$ & $0.23 * * *$ & $0.14 * * *$ & & & & & & & & & \\
\hline 6. SafeE & $0.19 * * *$ & $0.12 * *$ & $0.16^{* * *}$ & 0 & $0.38 * * *$ & & & & & & & & \\
\hline 7. ValueS & $0.15^{* * *}$ & $0.12 * *$ & $0.17 * * *$ & $0.11^{*}$ & $0.20 * * *$ & $0.17 * * *$ & & & & & & & \\
\hline 8. FutureG & 0.06 & $0.08 *$ & 0.08 & 0.08 & $0.14 * * *$ & $0.17 * * *$ & $0.35 * * *$ & & & & & & \\
\hline 9. ExternalM & $0.11 * *$ & $0.14 * * *$ & $0.15^{* * *}$ & 0.05 & $0.24 * * *$ & 0.01 & $0.08^{*}$ & $0.10^{*}$ & & & & & \\
\hline 10. InternalM & $0.14 * * *$ & $0.13^{* *}$ & $0.14 * *$ & $0.09 *$ & 0.05 & -0.01 & 0.07 & 0.07 & $0.24 * * *$ & & & & \\
\hline 11. DemonAb & $0.21 * * *$ & $0.25 * * *$ & $0.22 * * *$ & 0.01 & $0.12 * *$ & 0.02 & 0.08 & 0.03 & $0.32 * * *$ & $0.10^{*}$ & & & \\
\hline 12. LnExper & 0.08 & 0.07 & $0.10^{*}$ & -0.04 & 0.08 & 0.07 & -0.06 & -0.04 & -0.02 & 0.01 & 0.03 & & \\
\hline 13. TopComt & $0.11 * *$ & $0.10 *$ & $0.09 *$ & 0.01 & 0.06 & 0.04 & 0.04 & -0.02 & $-0.17 * * *$ & -0.04 & $-0.09 *$ & $0.40 * * *$ & \\
\hline$M$ & 3.35 & 3.68 & 3.34 & 2.25 & 3.22 & 3.18 & 3.07 & 3.47 & 1.94 & 2.55 & 2.71 & 4.72 & 3.25 \\
\hline$S D$ & 0.53 & 0.39 & 0.50 & 0.61 & 0.63 & 0.51 & 0.60 & 0.70 & 0.66 & 0.83 & 0.44 & 0.69 & 1.14 \\
\hline
\end{tabular}

ResAb: Resilience ability, ResBlf: Resilience beliefs, ResAttd: Resilience attitude, Com: competence AdultS: Adult support and help, SafeE: Safe environments, ValueS: Value of school learning, FutureG: School for future goals IntrinM: Intrinsic motivation, ExtrinM: Extrinsic motivation, DemonAb: Competence demonstration LnExper: Positive learning experience, TopComt: Commitment to learning topics and activities ${ }^{*} p<.05 ; * * p<.010 ; * * * p<.001$

competence demonstration motivations than the Lower Asset group. These results suggest that the participants who have higher personal and ecological assets are more motivated for self-driven learning.

\section{RQ3 Difference among the Identified Clusters Concerning Engagement in Self-Driven Learning}

As shown in Table 4, the t-tests analysis between the High Asset group and Lower Asset group on engagement in selfdriven learning (e.g., positive learning experiences and commitment to learning topics and activities) did not show any significant difference, suggesting the participants tended to have similar positive learning experiences and commitment to learning topics and activities at GripTape regardless of their personal and ecological assets.

\section{RQ4 Factors Correlating with Adolescents' Reflections on Self-Driven Learning}

As shown in Table 5, the multiple regression analysis indicated that participants' personal and ecological assets, motivation for self-driven learning, and cluster membership explained $3.1 \%$ of their positive learning experiences at GripTape. However, none of the factors significantly correlate with participants' positive learning experiences in self-driven learning.
Table 6 shows the multiple regression analysis of participants' personal and ecological assets, motivations for selfdriven learning, and cluster membership correlating with their commitment to learning topics and activities through the learning challenge. These factors explained $6.5 \%$ of participants' commitment to learning topics and activities. Extrinsic motivation $(\beta=-0.31, p<.01)$ and competence demonstration $(\beta=-0.23, p<.01)$ negatively correlate with participants' commitment to learning topics and activities, indicating the adolescents who were motivated by external factors or aimed to demonstrate their competence were less likely to commit to their chosen topics and activities.

\section{Discussion}

\section{Main Findings and Explanations}

This study identified unique profiles based on the personal and ecological assets of adolescents who participated in the GripTape self-driven learning program, examined how their motivations for and engagement in self-driven learning differ, and explored what factors correlate with their engagement. Several findings were noteworthy.

The adolescents who participated in this project had a higher intrinsic motivation level than extrinsic motivation (see Table 1). This result suggests that learners' intrinsic motivation does not necessarily become weaker than 


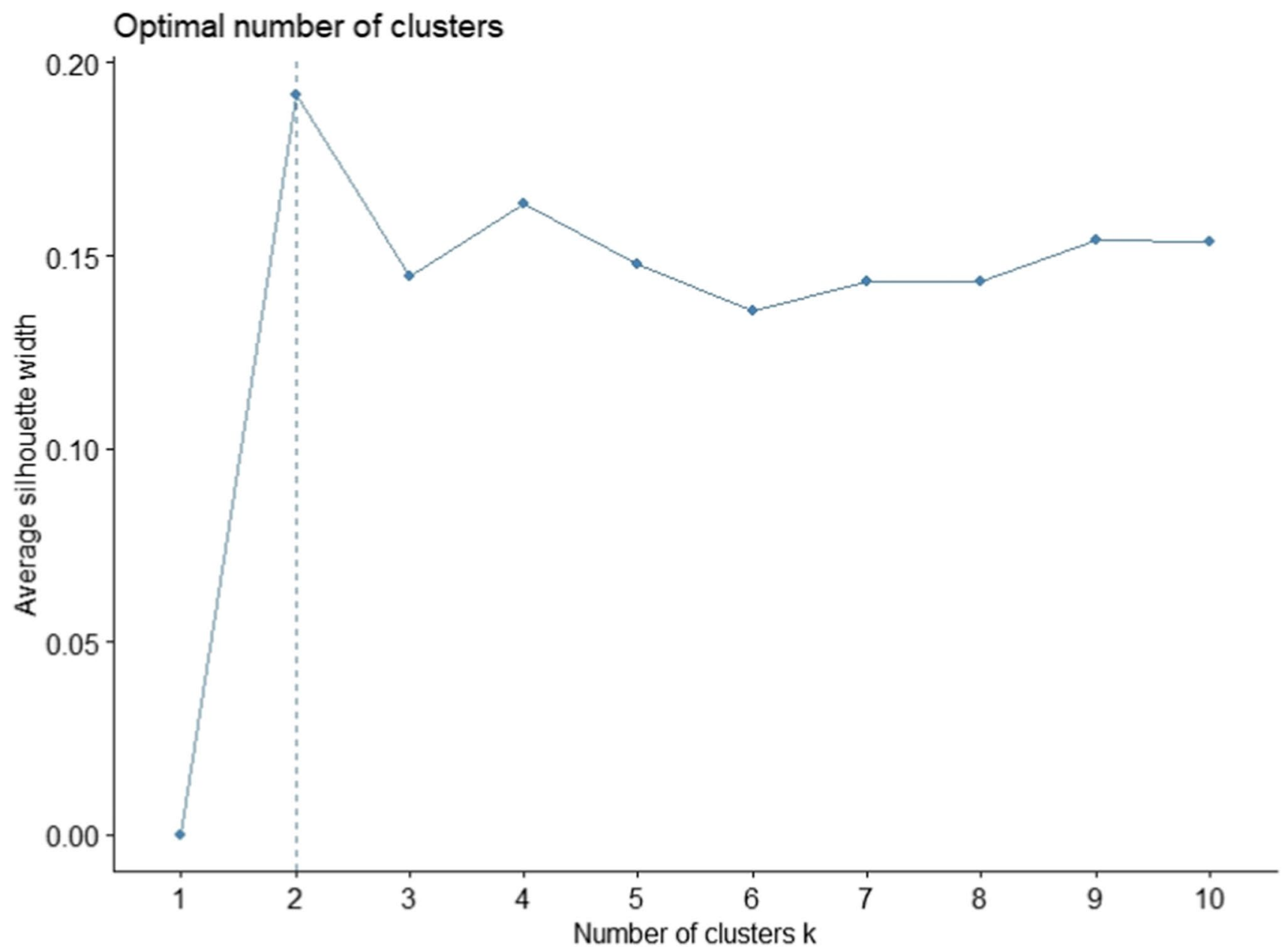

Fig. 1 Silhouette statistics with all participants' input elements

Table 2 Two clusters categorized based on adolescents' personal and ecological assets

\begin{tabular}{lll}
\hline Input variables & $\begin{array}{l}\text { Cluster 1: High } \\
\text { asset group } \\
(\mathrm{n}=317)\end{array}$ & $\begin{array}{l}\text { Cluster 2: Lower } \\
\text { Asset group } \\
(\mathrm{n}=263)\end{array}$ \\
\hline Resilience ability & $3.50^{* * *}$ & 3.15 \\
Resilience beliefs & $3.79 * * *$ & 3.54 \\
Resilience attitude & $3.45 * * *$ & 3.19 \\
Competence & $2.34 * * *$ & 2.15 \\
Adult support and help & $3.47 * * *$ & 2.91 \\
Safe environments & $3.35^{* * *}$ & 2.98 \\
Value of school learning & $3.31 * * *$ & 2.76 \\
School for future goals & $3.90^{* * *}$ & 2.93 \\
\hline
\end{tabular}

$* * * p<.001$

extrinsic motivation as they age (Ryan \& Deci, 2000). The autonomy and meaningfulness principles of motivation help explain this finding (Kumar et al., 2018). Self-driven learning enables the participants to take a high level of autonomy, control, and responsibility. A greater sense of autonomy is likely to enhance learners' intrinsic motivation (Ryan \& Deci, 2017). Furthermore, as the participants were empowered to choose the topics that they cared about, they were likely to pursue what they consider most meaningful and relevant to them. Toshalis and Nakkula (2012) also suggested that when the youth are given more opportunities to exercise choice, control, challenge, and collaboration, their motivation and engagement tend to rise. Similarly, Müller and Louw (2004) found that university students' perceived autonomy and competence are correlated with their intrinsic motivation, study interest, and self-determined forms of extrinsic motivation. The current study presents empirical evidence that adolescents can maintain high intrinsic motivation when provided with opportunities and resources to pursue what they are passionate about. With appropriate conditions, we can help adolescents fulfill their potentials of being active, inquisitive, and curious creatures who explore the world around them (Vansteenkiste et al., 2006). 
Table 3 Descriptive data of the two clusters on motivations for self-driven learning

\begin{tabular}{|c|c|c|c|c|c|c|}
\hline & \multicolumn{2}{|c|}{ Intrinsic motivation } & \multicolumn{2}{|c|}{ Extrinsic motivation } & \multicolumn{2}{|c|}{$\begin{array}{l}\text { Competence demon- } \\
\text { stration }\end{array}$} \\
\hline & $M$ & $S D$ & $M$ & $S D$ & $M$ & $S D$ \\
\hline High asset group & $2.64 * *$ & .77 & $2.03 * * *$ & .68 & $2.77 * * *$ & .39 \\
\hline Lower Asset group & 2.45 & .90 & 1.83 & .62 & 2.63 & .49 \\
\hline
\end{tabular}

$* * p<.01 ; * * * p<.001$

Table 4 Descriptive data of the two clusters on positive learning experiences and commitment to learning topics and activities

\begin{tabular}{|c|c|c|c|c|}
\hline & \multicolumn{2}{|c|}{$\begin{array}{l}\text { Positive learning } \\
\text { experiences }\end{array}$} & \multicolumn{2}{|c|}{$\begin{array}{l}\text { Commitment to } \\
\text { learning topics } \\
\text { and activities }\end{array}$} \\
\hline & $M$ & $S D$ & $M$ & $S D$ \\
\hline High asset group & 4.74 & .70 & 3.29 & 1.18 \\
\hline Lower Asset group & 4.69 & .66 & 3.21 & 1.10 \\
\hline
\end{tabular}

Using cluster analysis, participants were classified into two distinct groups with significant differences in personal and ecological assets. Consistent with previous studies (Cury et al., 2006; Mahoney et al., 2009), this result further confirms the interconnection between individuals' resilience, competence, and ecological assets as these constructs can profile participants into distinct groups, and one group scored higher on all of these factors while the other group scored lower on all factors. Furthermore, the High Asset group had significantly higher intrinsic, extrinsic, and competence demonstration motivations than the Lower Asset group. Previous studies have mainly researched how students' motivation is affected by their psychological needs (i.e., competence, autonomy, and relatedness) and social and environmental factors that influence these psychological needs (see Bureau et al., 2021 for a review). Students experiencing competence tend to be confident that their actions can significantly shape their academic experience; experiencing autonomy are likely to engage in learning tasks voluntarily; experiencing relatedness feel connected with important others for their learning (e.g., teachers, peers, Bureau et al., 2021; Ryan \& Deci, 2000). These psychological needs can be better satisfied when students can benefit from supportive environments. Both the self-determination (Ryan \& Deci, 2017) and expectancy-value theories (Wigfield et al., 2015) emphasize the importance of social context (i.e., parents and teachers) in explaining adolescents' differences in terms of intrinsic motivation and achievement. Diaconu-Gherasim et al. (2020) found that adolescents who experience lower parental rejection and greater teacher support show greater mastery goals and perceived higher competence, which are associated with intrinsic motivation. However, to our best knowledge, few studies have considered youth personal and ecological assets as a whole and examined how youth with
Table 5 Regression results using positive learning experience as the criterion

\begin{tabular}{|c|c|c|c|c|c|}
\hline Predictor & $b$ & $\begin{array}{l}b \\
95 \% \mathrm{CI} \\
{[\mathrm{LL}, \mathrm{UL}]}\end{array}$ & $s r^{2}$ & $\begin{array}{l}s r^{2} \\
95 \% \text { CI } \\
{[\mathrm{LL}, \mathrm{UL}]}\end{array}$ & Fit \\
\hline (Intercept) & $4.71 * *$ & {$[3.57,5.86]$} & & & \\
\hline Competence & -0.05 & {$[-0.15,0.04]$} & .00 & {$[-.01, .01]$} & \\
\hline Resilience ability & 0.03 & {$[-0.10,0.15]$} & .00 & {$[-.00, .00]$} & \\
\hline Resilience beliefs & 0.02 & {$[-0.16,0.19]$} & .00 & {$[-.00, .00]$} & \\
\hline Resilience attitude & 0.09 & {$[-0.04,0.22]$} & .00 & {$[-.01, .01]$} & \\
\hline Adult support and help & 0.06 & {$[-0.05,0.17]$} & .00 & {$[-.01, .01]$} & \\
\hline Safe environments & 0.05 & {$[-0.08,0.17]$} & .00 & {$[-.00, .01]$} & \\
\hline Value of school learning & -0.11 & {$[-0.21,0.00]$} & .01 & {$[-.01, .02]$} & \\
\hline School for future goals & -0.08 & {$[-0.20,0.04]$} & .00 & {$[-.01, .01]$} & \\
\hline Extrinsic motivation & -0.06 & {$[-0.15,0.04]$} & .00 & {$[-.01, .01]$} & \\
\hline Intrinsic motivation & 0.01 & {$[-0.06,0.08]$} & .00 & {$[-.00, .00]$} & \\
\hline Competence demonstration & 0.03 & {$[-0.11,0.17]$} & .00 & {$[-.00, .00]$} & \\
\hline \multirow[t]{3}{*}{ Cluster } & -0.12 & {$[-0.32,0.09]$} & .00 & {$[-.01, .01]$} & \\
\hline & & & & & $R^{2}=.031$ \\
\hline & & & & & $95 \% \mathrm{CI}[.00, .04]$ \\
\hline
\end{tabular}

A significant $b$-weight indicates the semi-partial correlation is also significant. $b$ represents unstandardized regression weights. $s r^{2}$ represents the semi-partial correlation squared. $L L$ and $U L$ indicate the lower and upper limits of a confidence interval, respectively.* indicates $\mathrm{p}<.05$. ** indicates $\mathrm{p}<.01$ 
Table 6 Regression results using topic commitment as the criterion

\begin{tabular}{llllll}
\hline Predictor & $\mathrm{b}$ & $\mathrm{b}$ & $\mathrm{s} 2$ & $\begin{array}{l}\text { sr2 } \\
95 \% \mathrm{CI} \\
{[\mathrm{LL}, \mathrm{UL}]}\end{array}$ & Fit \\
& & & & \\
\hline Intercept) & $2.19^{*}$ & {$[0.31,4.07]$} & & & \\
Competence & -0.01 & {$[-0.16,0.15]$} & .00 & {$[-.00, .00]$} & \\
Resilience ability & 0.19 & {$[-0.02,0.40]$} & .01 & {$[-.01, .02]$} & \\
Resilience beliefs & 0.22 & {$[-0.06,0.51]$} & .00 & {$[-.01, .01]$} & \\
Resilience attitude & 0.12 & {$[-0.10,0.33]$} & .00 & {$[-.00, .01]$} & \\
Adult support and help & 0.15 & {$[-0.03,0.32]$} & .00 & {$[-.01, .01]$} & \\
Safe environments & -0.04 & {$[-0.24,0.17]$} & .00 & {$[-.00, .00]$} & \\
Value of school learning & 0.08 & {$[-0.09,0.25]$} & .00 & {$[-.00, .01]$} & \\
School for future goals & -0.03 & {$[-0.22,0.16]$} & .00 & {$[-.00, .00]$} & \\
Extrinsic motivation & $-0.31^{* *}$ & {$[-0.46,-0.15]$} & .03 & {$[.00, .05]$} & \\
Intrinsic motivation & -0.02 & {$[-0.14,0.09]$} & .00 & {$[-.00, .00]$} & \\
Competence demonstration & $-0.23^{*}$ & {$[-0.46,-0.00]$} & .01 & {$[-.01, .02]$} & \\
Cluster & 0.06 & {$[-0.28,0.39]$} & .00 & {$[-.00, .00]$} & \\
& & & & & R2=.065** \\
& & & & & $95 \%$ CI $[.02, .09]$ \\
\hline
\end{tabular}

A significant $b$-weight indicates the semi-partial correlation is also significant. $b$ represents unstandardized regression weights. $s r^{2}$ represents the semi-partial correlation squared. $L L$ and $U L$ indicate the lower and upper limits of a confidence interval, respectively.* indicates $\mathrm{p}<.05$. ** indicates $\mathrm{p}<.01$ different profiles of personal and ecological assets differ in motivation. This study has extended the literature by clustering the youth based on their overall personal and ecological assets and examining their specific motivation for self-driven learning.

Furthermore, this result indicates that the High Asset adolescents in the formal learning context, also tend to have greater motivations in new informal learning contexts. This result is different from our conjecture that the self-driven learning project will especially attract the students who do not feel belonged or are valued in the formal school learning context. Rather, the students who perceive higher personal and ecological assets, tend to have greater motivations for self-driven learning. However, this result is not surprising, given the importance of competence, resilience, and ecological assets to motivation (Dweck \& Leggett, 1988). Moreover, this result suggests that the assets that adolescents develop in schools can motivate them to explore self-driven learning.

The greater motivation of the High Asset group does not result in greater engagement. Both the High Asset group and Lower Asset group had very high levels of positive learning experiences and did not significantly differ in terms of engagement in self-driven learning. Similarly, the regression analyses suggested that the group membership did not correlate with positive learning experiences or commitment to learning topics and activities. The results of the current study may be explained from the perspectives of learners' autonomy and academic relevancy. As discussed above, the self-determined theory suggests that students tend to perceive that they are freely and voluntarily engaging in learning tasks when they are experiencing autonomy (Ryan $\&$ Deci, 2000). When learners are in autonomous regulation conditions in which they do work because of "I wanted to do it" rather than "I had to do it", they tend to have more positive experiences such as being happy, free, concentrated, and in control (Bassi \& Delle Fave, 2012). Academic relevancy is the extent to which a learner perceives the current task to be useful and relevant to future goals (Crumpton \& Gregory, 2011). Crumpton and Gregory (2011) found that for low-achieving students, academic relevancy serves as a protective factor against academic disengagement, and intrinsic motivation mediates the relationship between academic relevancy and engagement. In this study, as the learning topics were chosen by the participants themselves based on their interests, they were likely to consider the learning content as relevant and meaningful. Furthermore, tasks connected to the "real world" beyond school can offer learners' a sense of ownership and purpose (Newmann et al., 2007). Such relevancy, purpose, and ownership could contribute to participants' positive learning experiences and commitment to learning topics and activities regardless of their personal and ecological assets before participating GripTape. As a result, individual initial differences do not have to be magnified across time, and the self-stabilizing cycles of motivation, engagement, and disaffection (Skinner \& Pitzer, 2012) can be changed. Future research is needed to verify this explanation.

Extrinsic motivation and competence demonstration negatively correlate with the commitment to learning topics and activities, which is not surprising. Participants 
who attended the self-driven learning with greater levels of external reasons and competence demonstration were less likely to commit to the learning topics and activities of their choosing in facing challenges. These results are consistent with the self-determination theory, which suggests that the extent to which learners are externally regulated is associated with their level of interest, value, or effort and adjustment coping styles when facing challenges (Ryan \& Deci, 2000). Similarly, Boyd (2002) suggested that when experiencing academic challenges, the students who are intrinsically motivated tend to persist. Walker et al. (2006) found that college students' intrinsic motivation was positively associated with their meaningful cognitive engagement (e.g., cognitive elaboration, creating complex knowledge structure); while their extrinsic motivation only contributed to shallow cognitive engagement (e.g., rote memorization, basic rehearsal).

\section{Implications}

Despite these considerations, this study provides important scientific and practical implications. Theoretically, it expands the self-determination theory by extending the context to self-driven learning. It implies the importance of empowering adolescents to drive their own learning as they did not differ in engagement regardless of their different personal and ecological assets, and motivations for self-driven learning. Given the connection between motivation, self-regulation, and resilience, Skinner and Pitzer (2012) indicated that future research should study how positive motivational dynamics promote self-regulation and resilience, and eventually help students take ownership of their learning and success. In this study, the participants had high intrinsic motivation and perceived high relevance of their learning challenges as they determined the learning topics. Future research can explicitly measure adolescents' perceived learning relevance, and investigate the relationships between intrinsic motivation, learning relevance, and engagement. Practically, it suggests the importance of considering youth intrinsic motivation when choosing learning content in out-of-school time programs because the ones who have greater levels of extrinsic motivation and competence demonstration rather than intrinsic motivation are less likely to commit to learning topics and activities. Furthermore, during the Covid19 pandemic, when lots of research are concerned about students' engagement in online learning (e.g., Ewing \& Cooper, 2021; Turnbull et al., 2021), this youth self-driven learning not only provides a possibility to complement students' formal learning but also provides implications regarding how to design learning opportunities to foster students' engagement in online learning.

\section{Strengths and Limitations}

This study adds to the literature by exploring different profiles of youth based on their personal and ecological assets in self-driven learning. It also extends the literature by examining the motivation for and engagement in self-driven learning of youth with different profiles. It contributes to the literature by suggesting that adolescents can maintain a high level of intrinsic and extrinsic motivation when they have the autonomy support to determine their learning topics and to control their learning process. Furthermore, this study suggests that regardless of youth personal and ecological assets, they had similar levels of positive learning experiences and topic and commitment to learning topics and activities at GripTape. Taken together, these results suggest the potential importance and effectiveness of youth self-driven learning in cultivating and sustaining youth motivation and engagement as well as fostering their positive development.

Albeit these strengths, there are noteworthy limitations of this research. First, this study is focused on youth who were enrolled in a single and unique self-driven learning program. Although GripTape shares many characteristics of other forms of self-driven learning or independent learning such as supporting learners' autonomy, control, and responsibility, a generalization of the current results to other programs and opportunities needs to be explored. Furthermore, the participants in this study are not a random sampling of adolescents in the United States. We instead intentionally included underrepresented youth in motivation research. Second, as an initial attempt to measure participants' resilience, ecological assets, motivation for self-driven learning, and engagement in self-driven learning, the scales employed in this study, although acceptable, can be improved in the future. For instance, there are only one or two items to measure some dimensions in some scales. The Cronbach's alphas for some factors are between 0.5 and 0.6. This may be due to the small number of items in these factors. Third, the data were obtained merely through the participants' self-report instruments. Therefore, this study shares the limitations of self-report measures such as being biased by responders' feelings and social desirability of looking good.

\section{Future Research Directions}

The above-mentioned limitations need to be addressed in future research. First, future research should re-test the clusters with other samples, using other datasets and in various self-driven learning projects. Second, this exploratory provides us with a better understanding of the structure and limitations of the scales (e.g., the scale of engagement for selfdriven learning), which will enable us to refine the scales in our future research to better understand youth engagement in self-driven learning. Finally, to complement and 
triangulate self-reported data, future research can include objective measures and collect participants' learning process data. For instance, to better understand the dynamics of students' motivation and engagement in self-driven learning, we are collecting audio recordings from the zoom meetings between youth and their dedicated adult supporters in which they frequently discuss youth learning progress and challenges throughout the self-driven learning program.

\section{Conclusions}

This study researched how youth personal and ecological assets converged into unique profiles, how youth with different profiles differ in motivation for and engagement in self-driven learning, and how these factors correlate with their engagement. We found that the youth can be classified into a High Asset group with higher personal and ecological assets, and a Lower Asset group who scored lower on these factors. The High Asset group also had higher motivations for self-driven learning than the Lower Asset group. However, the two groups did not differ in terms of engagement in self-driven learning, suggesting youth tended to have similar engagement levels at the program regardless of their personal and ecological assets, and motivations for selfdriven learning. This study represents our first attempt to study youth engagement in self-driven learning and extends the research on engagement in the out-of-school context. It sheds light on the features that promote or hinder youth engagement and triggers questions for future research (e.g., how to enhance youth engagement in self-driven learning).

Supplementary Information The online version contains supplementary material available at https://doi.org/10.1007/s12144-021-02412-0.

Acknowledgments This work is supported by the Silicon Valley Community Foundation under grant number 136823. Any findings, opinions, or recommendations expressed in this paper are those of the authors and do not necessarily reflect the views of the funding agency. The authors are indebted to Mark Murphy, Catherine Holland, and Melody Estevez for initiating and operating the GripTape project. We also like to thank all the incredible participants who allowed us to explore a new form of learning and made this research possible.

Data Availability Derived data supporting the findings of this study are available from the corresponding author upon reasonable request and with the permission of GripTape.

\section{Declarations}

Conflict of Interest There is no potential conflict of interest in the work.

Ethical Approval The data set was collected by the GripTape team (https://griptape.org/) for internal evaluation and future research purposes. The Institutional Review Board at the authors' university waived the ethics protocol review because we do not have access to the pri- vate identifiable information of the participants nor any master list that would allow the re-identification of the data.

Consent to Participate Our study does not meet the definition of human subjects research because we only analyzed the participants' surveys collected by GripTape after the learning activities were done and we did not have access to the private identifiable information and would never have access to any master list that would allow the re-identification of the data. Therefore, no informed consent forms were collected from the participants who were not directly involved in this study.

\section{References}

Ahmed, Y., Taha, M. H., Al-Neel, S., \& Gaffar, A. M. (2018). Students' perception of the learning environment and its relation to their study year and performance in Sudan. International Journal of Medical Education, 9, 145-150. https://doi.org/10.5116/ijme. 5af0.1fee

Bandura, A. (1999). Social cognitive theory: An agentic perspective. Asian Journal of Social Psychology, 2(1), 21-41. https://doi.org/ 10.1146/annurev.psych.52.1.1

Bassi, M., \& Delle Fave, A. (2012). Optimal experience and self-determination at school: Joining perspectives. Motivation and Emotion, 36(4), 425-438. https://doi.org/10.1007/s11031-011-9268-z

Bell, J., Besley, J., Cannady, M., Crowley, K., Grack Nelson, A., Philips, T., et al. (2019). The role of engagement in STEM learning and science communication: Reflections on interviews from the field. Center for Advancement of Informal Science Education.

Bergey, B. W., \& Ranellucci, J. (2021). Motivation profiles of urban preservice teachers: Relations to socialization, initial career perceptions, and demographics. Contemporary Educational Psychology, 64, 101936. https://doi.org/10.1016/j.cedpsych.2020.101936

Boyd, F. B. (2002). Motivation to continue: Enhancing literacy learning for struggling readers and writers. Reading and Writing Quarterly: Overcoming Learning Difficulties, 18, 257-277. https://doi.org/10. 1080/07487630290061818

Broad, J. (2006). Interpretations of independent learning in further education. Journal of Further and Higher Education, 30(02), 119-143. https://doi.org/10.1080/03098770600617521

Buja, A., \& Eyuboglu, N. (1992). Remarks on parallel analysis. Multivariate Behavioral Research, 27(4), 509-540. https://doi.org/10. 1207/s15327906mbr2704_2

Bureau, J. S., Howard, J. L., Chong, J. X., \& Guay, F. (2021). Pathways to student motivation: A meta-analysis of antecedents of autonomous and controlled motivations. Review of Educational Research, 00346543211042426. https://doi.org/10.3102/00346 543211042426

Cerasoli, C. P., Nicklin, J. M., \& Ford, M. T. (2014). Intrinsic motivation and extrinsic incentives jointly predict performance: A 40-year meta-analysis. Psychological Bulletin, 140(4), 980-1008. https://doi.org/10.1037/a0035661

Christenson, S. L., Reschly, A. L., \& Wylie, C. (2012). The handbook of research on student engagement. Springer Science.

Cronbach, L. J. (1951). Coefficient alpha and the internal structure of tests. Psychometrika, 16, 297-334. https://doi.org/10.1007/BF023 10555

Crumpton, H. E., \& Gregory, A. (2011). "I'm not learning”: The role of academic relevancy for low-achieving students. The Journal of Educational Research, 104(1), 42-53. https://doi.org/10.1080/ 00220670903567398

Csikszentmihalyi, M., \& Schneider, B. (2000). Becoming adult: How teenagers prepare for the world of work. Basic Books. 
Cury, F., Elliot, A. J., Da Fonseca, D., \& Moller, A. C. (2006). The social-cognitive model of achievement motivation and the $2 \times 2$ achievement goal framework. Journal of Personality and Social Psychology, 90, 666-679. https://doi.org/10.1037/0022-3514. 90.4.666

Dahl, R. E., Allen, N. B., Wilbrecht, L., \& Suleiman, A. B. (2018). Importance of investing in adolescence from a developmental science perspective. Nature, 554(7693), 441-450. https://doi.org/10. 1038/nature25770

Deci, E. L., \& Ryan, R. M. (1985). Intrinsic motivation and self-determination in human behavior. Plenum. https://doi.org/10.1007/ 978-1-4899-2271-7

Diaconu-Gherasim, L. R., Brumariu, L. E., \& Hurley, J. G. (2020). Adolescents' perceptions of contextual factors: Links with intrinsic motivation and academic achievement. Current Psychology, 1-16. https://doi.org/10.1007/s12144-020-01076-6

Dweck, C. S., \& Leggett, E. L. (1988). A social-cognitive approach to motivation and personality. Psychological Review, 95, 256-273. https://doi.org/10.1037/0033-295X.95.2.256

Earl, S. R., Taylor, I. M., Meijen, C., \& Passfield, L. (2017). Autonomy and competence frustration in young adolescent classrooms: Different associations with active and passive disengagement. Learning and Instruction, 49, 32-40. https://doi.org/10.1016/j.learninstr uc.2016.12.001

Ewing, L. A., \& Cooper, H. B. (2021). Technology-enabled remote learning during COVID-19: Perspectives of Australian teachers, students and parents. Technology, Pedagogy and Education, 30(1), 41-57. https://doi.org/10.1080/1475939X.2020.1868562

Fabrigar, L. R., \& Wegener, D. T. (2011). Exploratory factor analysis. Oxford University Press.

Ferlazzo, L. (2013). Self-driven learning: Teaching strategies for student motivation. Routledge.

Gottfried, A. E., Fleming, J. S., \& Gottfried, A. W. (2001). Continuity of academic intrinsic motivation from childhood through late adolescence: A longitudinal study. Journal of Educational Psychology, 93(1), 3-13. https://doi.org/10.1037/0022-0663.93.1.3

GripTape. (2017). Framework for facilitating the emergence of learner agency. Site name. https://griptape.org/wp-content/uploads/2017/ 11/GripTape-Learner-Agency-Framework.pdf

GripTape. (2021). Learning challenge overview. https://griptape.org/ wp-content/uploads/2021/04/Learning-Challenge_Overview.pdf

Hair Jr., J. F., Black, W. C., Babin, B. J., Anderson, R. E., \& Tatham, R. L. (1998). Multivariate data analysis with readings. Prentice-Hall.

Hamid, B., Faroukh, A., \& Mohammadhosein, B. (2013). Nursing students' perceptions of their educational environment based on DREEM model in an Iranian university. The Malaysian Journal of Medical Sciences: MJMS, 20(4), 56.

Hu, L. T., \& Bentler, P. M. (1999). Cutoff criteria for fit indexes in covariance structure analysis: Conventional criteria versus new alternatives. Structural Equation Modeling: A Multidisciplinary Journal, 6(1), 1-55. https://doi.org/10.1080/10705519909540118

Kaufman, L., \& Rousseeuw, P. J. (2009). Finding groups in data: An introduction to cluster analysis (Vol. 344). John Wiley \& Sons. https://doi.org/10.1002/9780470316801

Klem, A. M., \& Connell, J. P. (2004). Relationships matter: Linking teacher support to student engagement and achievement. Journal of School Health, 74(7), 262-273. https://doi.org/10.1111/j.17461561.2004.tb08283.x

Kopzhassarova, U., Akbayeva, G., Eskazinova, Z., Belgibayeva, G., \& Tazhikeyeva, A. (2016). Enhancement of students' independent learning through their critical thinking skills development. International Journal of Environmental and Science Education, 11(18), 11585-11592.

Kumar, R., Zusho, A., \& Bondie, R. (2018). Weaving cultural relevance and achievement motivation into inclusive classroom cultures.
Educational Psychologist, 53(2), 78-96. https://doi.org/10.1080/ 00461520.2018 .1432361

Lee, S. H. (2020). A community arts program for underserved children: Getting things done and member development. SciMedicine Journal, 2(3), 138-150. https://doi.org/10.28991/SciMe dJ-2020-0203-4

Lizzio, A., Wilson, K., \& Simons, R. (2002). University students' perceptions of the learning environment and academic outcomes: Implications for theory and practice. Studies in Higher Education, 27(1), 27-52. https://doi.org/10.1080/03075070120099359

Mahoney, J. L., Vandell, D., Simkins, S., \& Zarrett, N. (2009). Adolescent out-of school activities. In R. Lerner \& L. Steinberg (Eds.), Handbook of adolescent psychology (pp. 228-269). John Wiley.

Meyer, W. R. (2010). Independent learning: A literature review and a new project. Paper presented at the British Educational Research Association Annual Conference, University of Warwick.

Motjolopane, I. (2021). Teaching research methodology: Studentcentered approach computing education undergraduate course. Emerging Science Journal, 5(1), 34-43. https://doi.org/10.28991/ esj-2021-01255

Müller, F. H., \& Louw, J. (2004). Learning environment, motivation and interest: Perspectives on self-determination theory. South Africa Journal of Psychology, 34(2), 169-190. https://doi.org/ 10.1177/008124630403400201

Newmann, F. M., King, M. B., \& Carmichael, D. L. (2007). Authentic instruction and assessment: Common standards for rigor and relevance in teaching academic subjects. Iowa Department of Education.

Parry, S. (2021). Fit indices commonly reported for CFA and SEM. Available at: www.cscu.cornell.edu/news/Handouts/SEM_fit.pdf. Accessed 14 Jan 2021.

Raufelder, D., \& Kulakow, S. (2021). The role of the learning environment in adolescents' motivational development. Motivation and Emotion, 45(3), 299-311. https://doi.org/10.1007/ s11031-021-09879-1

Revelle, W. (2020). Package 'psych'. Retrieved from https://cran.rproject.org/web/packages/psych/psych.pdf

Reynolds, R., \& Caperton, I. H. (2011). Contrasts in student engagement, meaning-making, dislikes, and challenges in a discoverybased program of game design learning. Educational Technology Research and Development, 59(2), 267-289. https://doi.org/10. 1007/s11423-011-9191-8

Rutter, M. (2006). Implications of resilience concepts for scientific understanding. Annals of the New York Academy of Sciences, 1094, 1-12. https://doi.org/10.1196/annals.1376.002

Ryan, R. M., \& Deci, E. L. (2000). Intrinsic and extrinsic motivations: Classic definitions and new directions. Contemporary Educational Psychology, 25(1), 54-67. https://doi.org/10.1006/ceps.1999.1020

Ryan, R. M., \& Deci, E. L. (2017). Self-determination theory: Basic psychological needs in motivation, development, and wellness. Guilford Press. https://doi.org/10.1521/978.14625/28806

Ryan, R. M., \& Deci, E. L. (2020). Intrinsic and extrinsic motivation from a self-determination theory perspective: Definitions, theory, practices, and future directions. Contemporary Educational Psychology, 61, 101860. https://doi.org/10.1016/j.cedpsych.2020. 101860

Schmidt, J. A., Beymer, P. N., Rosenberg, J. M., Naftzger, N. N., \& Shumow, L. (2020). Experiences, activities, and personal characteristics as predictors of engagement in STEM-focused summer programs. Journal of Research in Science Teaching, 57(8), 1281-1309.

Shernoff, D. J., \& Vandell, D. L. (2007). Engagement in after-school program activities: Quality of experience from the perspective of participants. Journal of Youth and Adolescence, 36(7), 891-903. https://doi.org/10.1007/s10964-007-9183-5 
Skinner, E. A., \& Pitzer, J. R. (2012). Developmental dynamics of student engagement, coping, and everyday resilience. In S. L. Christenson, A. L. Reschly, \& C. Wylie (Eds.), Handbook of research on student engagement (pp. 21-44). Springer.

Steinberg, L. (2015). New foundations of adolescent learning: Lessons from behavioral science, social science, and neuroscience. Independent School, 74(3), n3.

Toshalis, E., \& Nakkula, M. J. (2012). Motivation, engagement, and student voice. In N. Hoffman, A. Steinberg, \& R. Wolfe (Eds.), The students at the center series (pp. 1-42). Jobs for the Future.

Turnbull, D., Chugh, R., \& Luck, J. (2021). Transitioning to E-learning during the COVID-19 pandemic: How have higher education institutions responded to the challenge? Education and Information Technologies, 1-19. https://doi.org/10.1007/s10639-021-10633-w

van Griethuijsen, R. A., van Eijck, M. W., Haste, H., den Brok, P. J., Skinner, N. C., Mansour, N., et al. (2015). Global patterns in students' views of science and interest in science. Research in Science Education, 45(4), 581-603. https://doi.org/10.1007/ s11165-014-9438-6

Vansteenkiste, M., Simons, J., Lens, W., Sheldon, K. M., \& Deci, E. L. (2004). Motivating learning, performance, and persistence: The synergistic effects of intrinsic goal contents and autonomysupportive contexts. Journal of Personality and Social Psychology, 87(2), 246-260. https://doi.org/10.1037/0022-3514.87.2.246
Vansteenkiste, M., Lens, W., \& Deci, E. L. (2006). Intrinsic versus extrinsic goal contents in self-determination theory: Another look at the quality of academic motivation. Educational Psychologist, 41(1), 19-31. https://doi.org/10.1207/s15326985e p4101_4

Walker, C. O., Greene, B. A., \& Mansell, R. A. (2006). Identification with academics, intrinsic/extrinsic motivation, and self-efficacy as predictors of cognitive engagement. Learning and Individual Differences, 16(1), 1-12. https://doi.org/10.1016/j.lindif.2005. 06.004

Wigfield, A., Eccles, J. S., Fredricks, J. A., Simpkins, S., Roeser, R. W., \& Schiefele, U. (2015). Development of achievement motivation and engagement. In M. E. Lamb \& R. M. Lerner (Eds.), Handbook of child psychology and developmental science: Socioemotional processes (pp. 657-700). John Wiley $\&$ Sons Inc..

Wu, G., Feder, A., Cohen, H., Kim, J. J., Calderon, S., Charney, D. S., \& Mathé, A. A. (2013). Understanding resilience. Frontiers in Behavioral Neuroscience, 7, 10. https://doi.org/10.3389/fnbeh. 2013.00010

Publisher's Note Springer Nature remains neutral with regard to jurisdictional claims in published maps and institutional affiliations. 